\title{
Intravenous Magnesium Sulfate versus Tramadol in Prevention of Post Spinal Shivering in Geriatric Patients Undergoing Transurethral Resection of Prostate
} Fatma Mahmoud Ahmed ${ }^{1}$, Ashraf Said Sayed ${ }^{1}$, Hala Ibrahim Zanfaly ${ }^{1}$, Jamaah Husayn Qareen*2 ${ }^{1}$ Department of Anesthesia and Surgical Intensive Care, Faculty of Medicine, Zagazig University, Egypt ${ }^{2}$ Department of Anesthesia and Surgical Intensive Care, Faculty of Medicine, Sirte University, Libya *Corresponding Author: Jamaah Husayn Qareen, Mobile: 00218917811001, E-mail: khaledgrain69@ gmail.com

\begin{abstract}
Background: Postanesthetic shivering is a frequent complication of anesthesia, perhaps even aggravating pain especially during transurethral rsection of prostate (TURP) surgery.

Objective: To compare the efficacy of I.V $\mathrm{MgSO}_{4}$ and tramadol to placebo normal saline on incidence and severity of postspinal shivering in geriatric patients undergoing TURP surgery, when used as prophylaxis.

Patients and methods: This was a comparative prospective study that included 39 geriatric male patients who scheduled for performing an elective TURP surgery under subarachnoid blockade (SAB) at Zagazig University Hospitals. Patients were divided equally into 3 groups: Group $\mathrm{C}$ received isotonic saline after spinal anesthesia, group $\mathrm{Mg}$ : received I.V $\mathrm{MgSO}_{4}$ in isotonic saline and group T: received I.V tramadol in isotonic saline after spinal anesthesia. All patients were enrolled for examination before and after surgery.

Results: There was no significant difference among the studied groups as regards HR, MAP and Spo2 between the three studied groups. Regarding changes in temperature between the studied groups, $\mathrm{C}$ group showed a significant lower temperature time followed by $\mathrm{Mg}$ group then $\mathrm{T}$ group at different times. There was a significant higher rate of shivering in $\mathrm{C}$ group then $\mathrm{Mg}$ group and the lowest was $\mathrm{T}$ group. Onset of shivering was significantly faster in control then $\mathrm{Mg}$ group and longer significantly in Group $\mathrm{T}$.

Conclusions: Prophylactic administration of I.V tramadol in a dose of $0.5 \mathrm{mg} / \mathrm{kg}$ immediately after SAB could significantly reduce the incidence and severity of postspinal shivering more than I.V MgSO 4 in a dose of $15 \mathrm{mg} / \mathrm{kg}$ in geriatric patients undergoing TURP surgery.
\end{abstract}

Keywords: Tramadol, $\mathrm{MgSO}_{4}$, Post Spinal Shivering, TURP.

\section{INTRODUCTION}

Spinal anesthesia is known to significantly impair thermoregulation and predispose patients to hypothermia $^{(\mathbf{1})}$. General and epidural anesthesia alter the function of the autonomic nervous system, which plays a significant role in thermoregulation and interferes primarily with peripheral vasoconstriction below the level of the sympathetic blockade ${ }^{(2)}$.

Shivering associated with spinal and epidural anesthesia is common, occurring in up to $56.7 \%$ of patients ${ }^{(3)}$. Shivering may interferes with monitoring of the electrocardiogram, blood pressure, and oxygen saturation. Furthermore, shivering increases oxygen consumption, lactic acidosis, carbon dioxide production, and metabolic rate by up to $400 \%$. Thus, it may cause problems in patients with low cardiac and pulmonary reserves (4). Shivering is an important problem for urologists, especially during transurethral resection of the prostate (TURP) surgery. Shivering may interfere with the surgeon's ability to visualize a resectable prostate tissue. Injury to the urethra, bladder, and rectum may occur during the procedure. As a result, shivering not only prolongs the operation time, it may also cause severe complications ${ }^{(5)}$.

Geriatric patients have a higher incidence of morbidity and mortality during surgery than young age. Also, geriatric patients who are undergoing TURP surgery have a cardiac risk because of medical problems. Hypothermia can complicate TURP surgery. Geriatric patients are predisposed to the risk of hypothermia, which induces shivering after spinal anesthesia ${ }^{(\boldsymbol{6})}$.

Magnesium sulfate $\left(\mathrm{MgSO}_{4}\right)$ has anti-shivering effects. But it may enhance the rate of cooling because of its vasodilatory properties. Furthermore, it has a potential neuroprotective effects, and experimental data suggest that the neuroprotective effect of hypothermia may be increased with the addition of $\mathrm{MgSO}_{4}{ }^{(7,8)}$.

Tramadol is a centrally acting weak $\mu$-opioid receptor analgesic. Administration of tramadol is the universally available cost-effective drug with the minimal side-effects. It is a cyclohexanol derivative, which has $\mu$ agonist activity as well as acts as an inhibitor of serotonin and norepinephrine uptake. It is metabolized in the liver and is mainly consumed as an analgesic ${ }^{(9)}$. Intravenous tramadol has been used for treatment of shivering. The use of oral tramadol $50 \mathrm{mg}$ is effective as a prophylactic agent to reduce the incidence, severity and duration of perioperative shivering in patients undergoing TURP surgery under subarachnoid blockade (SAB) ${ }^{(10)}$. The analgesic potency of tramadol is found to be a ten times lesser than morphine but is preferred being safe than the later. Tramadol is considered safe, as it does not cause respiratory depression and addiction when compared to 
other opioid analgesics ${ }^{(11)}$. So far, there was no study to compare the effect of intravenous $\mathrm{MgSO}_{4}$ with i.v. tramadol on post-spinal anesthesia shivering.

The aim of the present study was to compare between i.v. $\mathrm{MgSO}_{4}$ and tramadol on incidence and severity of shivering in geriatric patients undergoing TURP surgery. Moreover to assess sensory and motor block and the highest level of sensory block in geriatric patients undergoing TURP surgery.

\section{PATIENTS and METHODS:}

A comparative prospective study included 39 geriatric male patients who were scheduled for performing an elective TURP surgery under the SAB at Zagazig University Hospitals.

Inclusion criteria: Male geriatric patients aged between 65 to 70 years old with BMI less than 35 $\mathrm{kg} / \mathrm{m}^{2}$ who were scheduled to undergo elective TURP surgery under SAB were enrolled in the study. Patients achieved the American Society of Anesthesiologists (ASA) physical status II and III.

Exclusion criteria: Patients who had any history suggestive of allergy to the study medications. Thyroid dysfunction. Severe diabetic or autonomic neuropathy. Infection of the urinary tract. History of administration of vasodilators or vasoconstrictors as those drugs could interfere with the body thermoregulation. Preoperative fever (temperature $\geq 38^{\circ} \mathrm{C}$ ).
Contraindications to spinal anesthesia. Parkinson's disease. Raynaud's syndrome.

\section{Ethical consent:}

An approval of the study was obtained from Zagazig University Academic and Ethical Committee. Every patient signed an informed written consent for acceptance of the operation. The work has been carried out in accordance with World Medical Association (Declaration of Helsinki) for studies involving humans.

\section{Operative design and management:}

Patients were divided equally into 3 groups: Group C $(n=13)$ received i.v. $100 \mathrm{~mL}$ of isotonic saline slowly after spinal anesthesia as control group, group $\mathrm{Mg}:(\mathrm{n}=13)$ received i.v. $\mathrm{Mg} \mathrm{SO}_{4} 15 \mathrm{mg} / \mathrm{kg}$ in $100 \mathrm{~mL}$ isotonic saline slowly after spinal anesthesia and Group T: $(\mathrm{n}=13)$ received i.v. tramadol $0.5 \mathrm{mg} / \mathrm{kg}$ in $100 \mathrm{~mL}$ isotonic saline slowly after spinal anesthesia (Fig. 1).

All patients were enrolled for examination before and after surgery. All patients were covered with one layer of surgical drapes over the chest, thighs, and calves during the operation, and one cotton blanket over the entire body postoperatively. No other warming device was used. Core temperature below $36^{\circ} \mathrm{C}$ was considered as hypothermia. Maximum sensory level was recorded. Degree of motor and sensory blockade was assessed intraoperatively every 5 minutes and also in the recovery unit.

\section{Consort flow diagram}

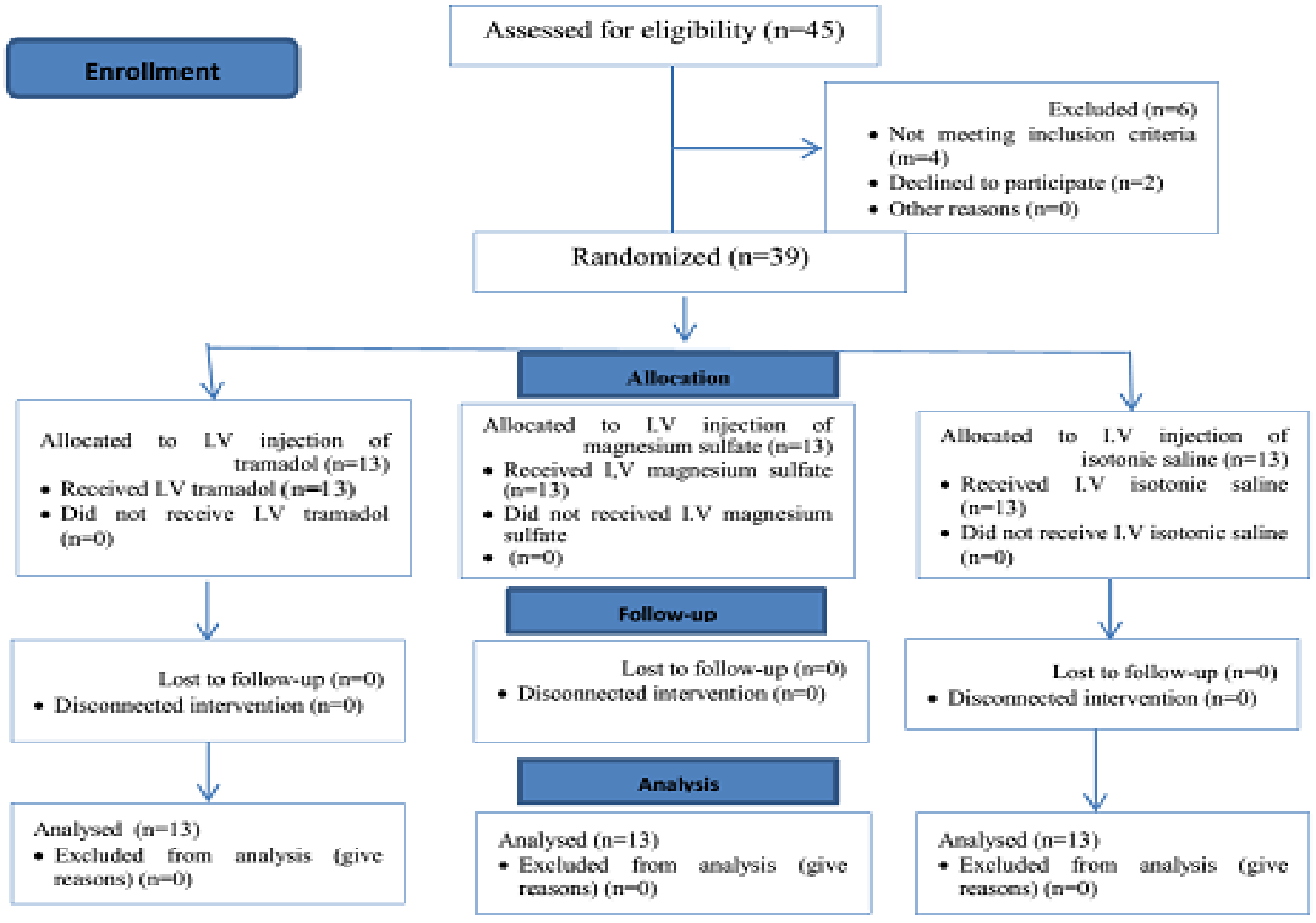

Figure (1): Flow diagram of patients enrolled in the study 
Mean arterial blood pressure, heart rate, peripheral oxygen saturation, tympanic temperature, sedation score and onset and duration of all were measured and recorded at the baseline before $\mathrm{SAB}$ and then every 5 minutes to the $1^{\text {st }} 30$ minutes after $S A B$ then at 45 minutes, then at the end of opereation and also at recovery room.

Shivering intensity was graded using a scale similar to that validated by Crossley and Mahajan ${ }^{(12)}$, where $0=$ no shivering, $1=$ piloerection or peripheral vasoconstriction but no visible shivering, $2=$ muscular activity in one muscle group only, $3=$ muscular activity in more than one muscle group and $4=$ whole body shivering.

\section{Statistical analysis}

Data collected throughout history, basic clinical examination, laboratory investigations and outcome measures were coded, entered and analyzed using Microsoft Excel software. Data were then imported into Statistical Package for the Social Sciences (SPSS version 20.0) software for analysis. According to the type of data, qualitative were represented as number and percentage, while quantitative were represented as mean $\pm \mathrm{SD}$. the following tests were used to test differences for significance; difference and association of qualitative variable by $\mathrm{Chi}$ square test $\left(\mathrm{X}^{2}\right)$. Differences between quantitative independent multiple by ANOVA. P value was set at $\leq 0.05$ for significant results $\&<0.001$ for highly significant result.

\section{RESULTS}

The attained results showed that HR at different times showed no significant difference between the three groups ( $p>0.05)$ (Table 1). As regards MAP and $\mathrm{SPO}_{2}$ at different times, there were no significant differences between the three groups $(\mathrm{p}>0.05)$ (Figure $2 \& 3$ respectively).

As regards the basal tympanic temperature, there was no significant difference among the three groups $(\mathrm{p}>0.05)$. However at different times $(5,10,15$, $20,25,30$ minutes), there was a highly significant decrease in tympanic temperature in control group $(\mathrm{p}<$ 0.001 ) at 45 minutes, at the end of operation and at the recovery room. There was a significant decrease in tympanic temperature in control group when compared to the other two groups $(\mathrm{p}<0.05)$. On the other hand, there was no significant differences in tympanic temperature at different times when comparing $\mathrm{Mg}$ group with $\mathrm{T}$ group $(\mathrm{p}>0.05)$ (Table 2$)$.

Concerning the onset of sensory and motor block, there was a significant delay in control group when compared to the other two groups $(\mathrm{p}<0.01)$. Durations of sensory block were $8.54 \pm 0.96,14.83 \pm$ 2.12 and $17.33 \pm 1.3$ minutes in control, magnesium and tramadol groups respectively with significant decrease $(p<0.05)$ in control group compared to the other two groups. There was no significant difference between magnesium and tramadol groups (Table 3).

Shivering occurred in 10 patients $(76.9 \%)$ in control group, in 4 patients $(30.8 \%)$ in magnesium group and in 1 patient $(7.7 \%)$ in tramadol group with significantly increased occurrence $(p<0.05)$ in control group compared to the other two groups. There was a significant rapid onset of shivering in control group when compared with the other two groups $(\mathrm{p}<0.01)$ (Figure 4).

Table (1): HR distribution at different times among the studied groups

\begin{tabular}{|c|c|c|c|c|c|}
\hline & Time & $\begin{array}{c}\text { Group C } \\
(\mathbf{N}=13)\end{array}$ & $\begin{array}{c}\text { Group mg } \\
(\mathbf{N}=13)\end{array}$ & $\begin{array}{c}\text { Group T } \\
(\mathbf{N}=13)\end{array}$ & $\mathbf{P}$ \\
\hline HR (beat/min) & Basal & $74.83 \pm 3.63$ & $74.58 \pm 2.99$ & $74.75 \pm 3.01$ & 0.982 \\
\hline HR (beat/min) & 5 & $78.87 \pm 4.36$ & $77.55 \pm 3.69$ & $77.89 \pm 4.69$ & 0.980 \\
\hline HR (beat/min) & $\mathbf{1 0}$ & $81.25 \pm 5.23$ & $80.25 \pm 4.45$ & $81.05 \pm 4.44$ & 0.978 \\
\hline HR (beat/min) & 15 & $80.55 \pm 6.58$ & $80.11 \pm 3.99$ & $79.11 \pm 5.21$ & 0.978 \\
\hline HR (beat/min) & 20 & $79.58 \pm 4.21$ & $78.11 \pm 3.12$ & $79.01 \pm 4.65$ & 0.988 \\
\hline HR (beat/min) & 25 & $84.23 \pm 4.25$ & $82.54 \pm 4.54$ & $83.47 \pm 4.87$ & 0.968 \\
\hline HR (beat/min) & 30 & $83.58 \pm 5.33$ & $81.14 \pm 3.25$ & $82.655 \pm 4.44$ & 0.969 \\
\hline HR (beat/min) & 45 & $82.54 \pm 4.32$ & $80.58 \pm 2.28$ & $81.76 \pm 2.35$ & 0.978 \\
\hline HR (beat/min) & $\begin{array}{l}\text { At the end of } \\
\text { operation }\end{array}$ & $78.95 \pm 3.33$ & $77.58 \pm 2.97$ & $78.25 \pm 4.21$ & 0.979 \\
\hline HR (beat/min) & $\begin{array}{c}\text { At the } \\
\text { recovery room }\end{array}$ & $76.54 \pm 4.21$ & $75.11 \pm 3.25$ & $75.14 \pm 3.25$ & 0.982 \\
\hline
\end{tabular}

Data are expressed as mean \pm SD, HR: heart rate, $\mathrm{P}>0.05$ was considered non-significant. 


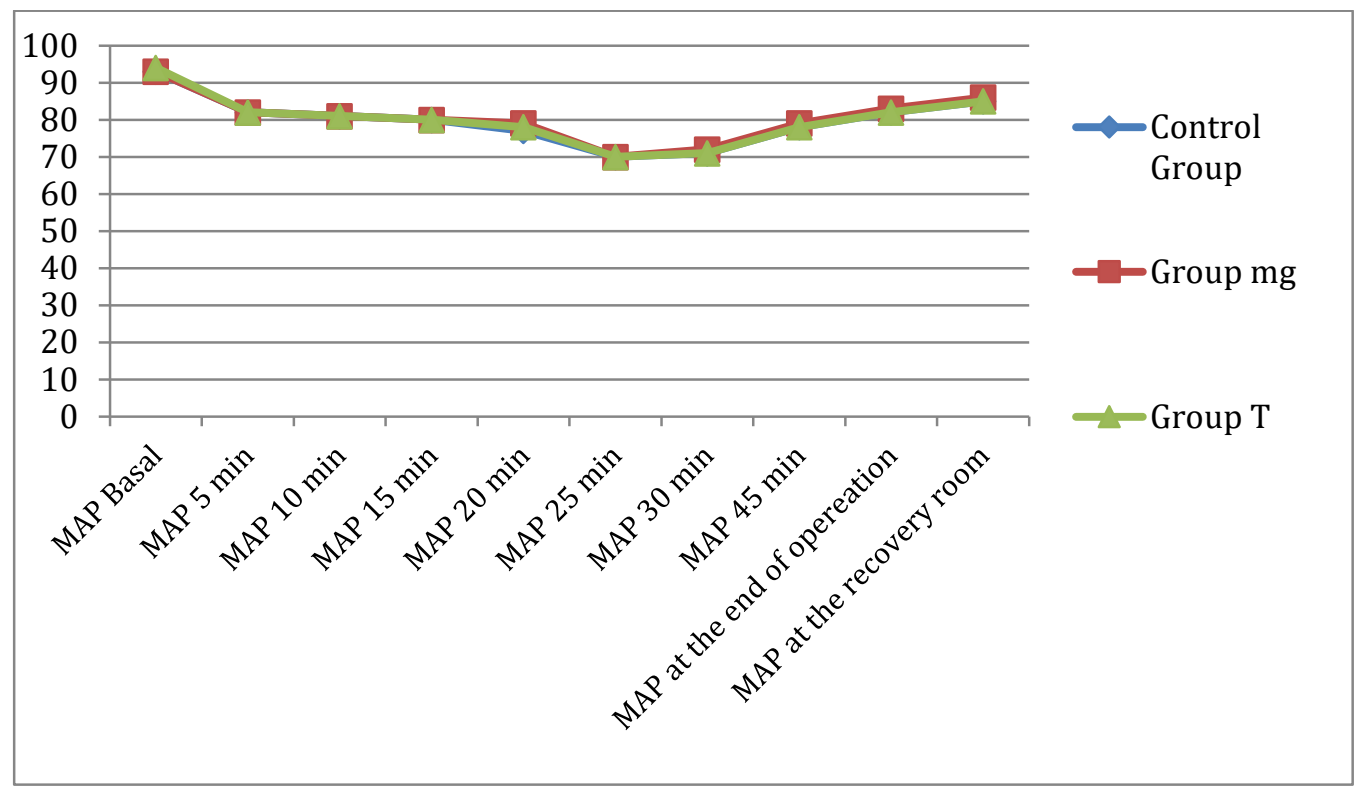

Figure (2): MAP distribution at different times among the three groups

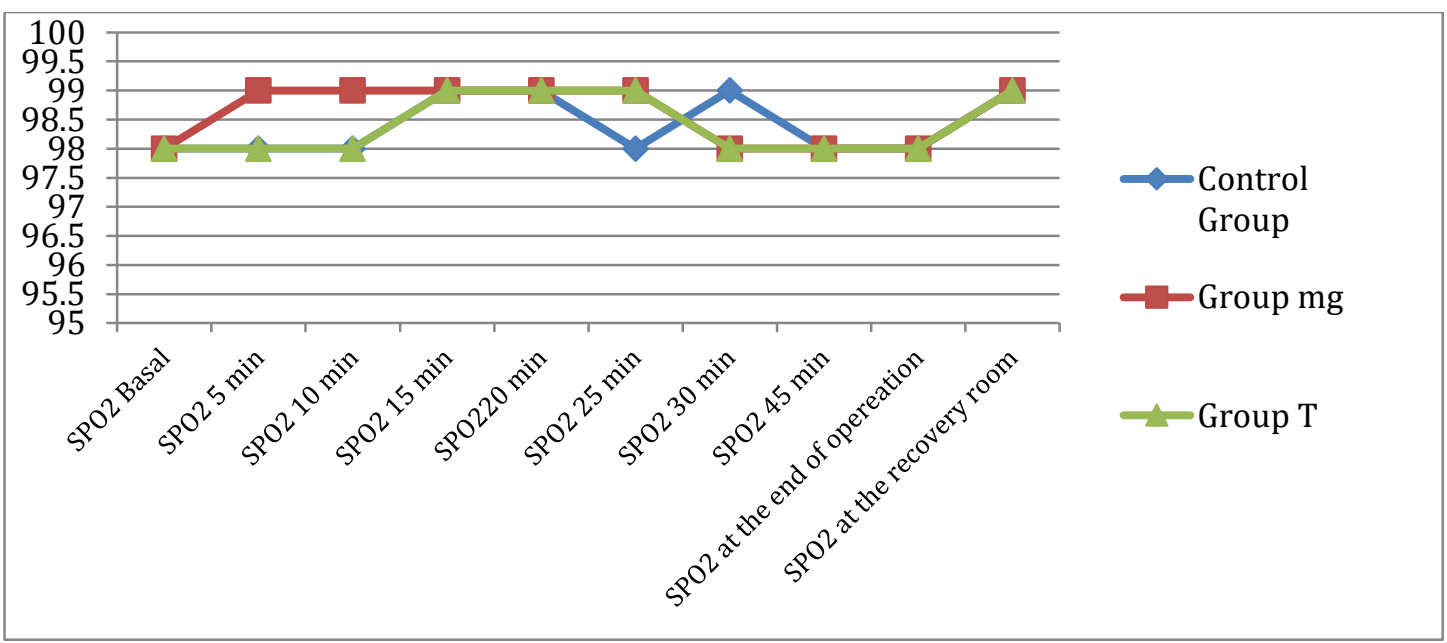

Figure (3): SPO2 distribution at different times among the three groups

Table (2): Temp distribution at different times among the three groups

\begin{tabular}{|c|c|c|c|c|c|}
\hline & Time & $\begin{array}{c}\text { Group C } \\
(\mathbf{N}=13)\end{array}$ & $\begin{array}{c}\text { Group mg } \\
(\mathbf{N}=13)\end{array}$ & $\begin{array}{c}\text { Group T } \\
(\mathbf{N}=13)\end{array}$ & $\mathbf{P}$ \\
\hline TEMP $^{\circ} \mathrm{C}$ & Basal & $36.96 \pm 0.75$ & $36.92 \pm 0.04$ & $36.96 \pm 0.06$ & 0.147 \\
\hline TEMP ${ }^{\circ} \mathrm{C}$ & 5 & $36.76 \pm 0.12$ & $\mathbf{3 6 . 8 5} \pm 0.07$ & $36.91 \pm 0.09$ & $\mathbf{0 . 0 0} * *$ \\
\hline TEMP ${ }^{\circ} \mathrm{C}$ & 10 & $36.66 \pm 0.12$ & $36.80 \pm 0.10$ & $36.90 \pm 0.10$ & $\mathbf{0 . 0 0} * *$ \\
\hline TEMP ${ }^{\circ} \mathrm{C}$ & 15 & $36.60 \pm 0.11$ & $36.85 \pm 0.12$ & $36.95 \pm 0.09$ & $\mathbf{0 . 0 0} * *$ \\
\hline TEMP ${ }^{\circ} \mathrm{C}$ & 20 & $36.55 \pm 0.10$ & $36.87 \pm 0.10$ & $36.91 \pm 0.09$ & 0.009* \\
\hline TEMP ${ }^{\circ} \mathrm{C}$ & 25 & $36.50 \pm 0.17$ & $36.75 \pm 0.16$ & $36.90 \pm 0.13$ & $0.00 * *$ \\
\hline TEMP ${ }^{\circ} \mathrm{C}$ & 30 & $36.48 \pm 0.20$ & $36.86 \pm 0.14$ & $36.94 \pm 0.06$ & $\mathbf{0 . 0 0} * *$ \\
\hline TEMP ${ }^{\circ} \mathrm{C}$ & 45 & $36.45 \pm 0.05$ & $36.86 \pm 0.09$ & $36.81 \pm 0.06$ & 0.049* \\
\hline TEMP $^{\circ} \mathrm{C}$ & $\begin{array}{l}\text { At the end of } \\
\text { the operation }\end{array}$ & $36.44 \pm 0.12$ & $36.93 \pm 0.10$ & $36.90 \pm 0.05$ & $0.026 *$ \\
\hline TEMP ${ }^{\circ} \mathrm{C}$ & $\begin{array}{c}\text { At the recovery } \\
\text { room }\end{array}$ & $36.55 \pm 0.08$ & $36.94 \pm 0.11$ & $36.95 \pm 0.10$ & $0.015^{*}$ \\
\hline
\end{tabular}

Data are expressed as mean \pm SD.P $>0.05$ was considered non-significant, $* \mathrm{p}<0.05$ was considered significant, $* * \mathrm{P}<$ 0.001 was considered highly significant. $\mathrm{N}=$ number. 
Table (3): Characteristics of sensory block, motor block and sedation score in the three studied groups

\begin{tabular}{|c|c|c|c|c|c|c|}
\hline & & & $\begin{array}{c}\text { Group C } \\
(\mathbf{N}=\mathbf{1 3})\end{array}$ & $\begin{array}{c}\text { Group mg } \\
(\mathrm{N}=13)\end{array}$ & $\begin{array}{c}\text { Group T } \\
(\mathrm{N}=13)\end{array}$ & $\mathbf{P}$ \\
\hline \multicolumn{3}{|c|}{ Onset of sensory block (min) } & $16.95 \pm 1.56$ & $14.95 \pm 0.99$ & $13.28 \pm 1.2$ & $\mathbf{0 . 0 0}$ ** \\
\hline \multicolumn{3}{|c|}{ Onset of motor block (min) } & $21.35 \pm 1.15$ & $18.88 \pm 0.86$ & $15.32 \pm 1.51$ & $0.00 * *$ \\
\hline \multicolumn{3}{|c|}{ Duration sensory block (min) } & $8.54 \pm 0.96$ & $14.83 \pm 2.12$ & $17.33 \pm 1.3$ & $\mathbf{0 . 0 0 * *}$ \\
\hline \multicolumn{3}{|c|}{ Duration motor block (min) } & $6.83 \pm 1.0$ & $10.66 \pm 1.37$ & $14.58 \pm 1.56$ & $0.00 * *$ \\
\hline \multicolumn{3}{|c|}{ Time of 2 segment regression(min) } & $68.88 \pm 12.5$ & $70.58 \pm 17.63$ & $70.97 \pm 17.48$ & 0.514 \\
\hline \multicolumn{3}{|c|}{ Sedation score } & $2.75 \pm 0.85$ & $2.62 \pm 0.76$ & $2.94 \pm 0.85$ & 0.385 \\
\hline \multirow{10}{*}{$\begin{array}{c}\text { Peak } \\
\text { sensory } \\
\text { level }\end{array}$} & \multirow[b]{2}{*}{ T7 } & $\mathbf{N}$ & 3 & 3 & 4 & \\
\hline & & $\%$ & $23.1 \%$ & $23.1 \%$ & $30.8 \%$ & \\
\hline & \multirow{2}{*}{ T8 } & $\mathbf{N}$ & 3 & 4 & 3 & \\
\hline & & $\%$ & $23.1 \%$ & $30.8 \%$ & $23.1 \%$ & \\
\hline & \multirow{2}{*}{ T9 } & $\mathbf{N}$ & 3 & 2 & 2 & \\
\hline & & $\%$ & $23.1 \%$ & $15.4 \%$ & $15.4 \%$ & 0.789 \\
\hline & \multirow[b]{2}{*}{ T10 } & $\mathbf{N}$ & 2 & 3 & 2 & \\
\hline & & $\%$ & $15.4 \%$ & $23.1 \%$ & $15.4 \%$ & \\
\hline & \multirow{2}{*}{ T11 } & $\mathbf{N}$ & 2 & 1 & 2 & \\
\hline & & $\%$ & $15.4 \%$ & $7.8 \%$ & $15.4 \%$ & \\
\hline \multirow{2}{*}{\multicolumn{2}{|c|}{ Total }} & $\mathbf{N}$ & 13 & 13 & 13 & \\
\hline & & $\%$ & $100.0 \%$ & $100.0 \%$ & $100.0 \%$ & \\
\hline
\end{tabular}

Data was expressed as mean $\pm \mathrm{SD}$,numbers and percentage. $\mathrm{N}=$ Number, min=minutes., $\mathrm{p}>0.05$ was considered nonsignificant, $* \mathrm{p}<0.05$ was considered significant difference.

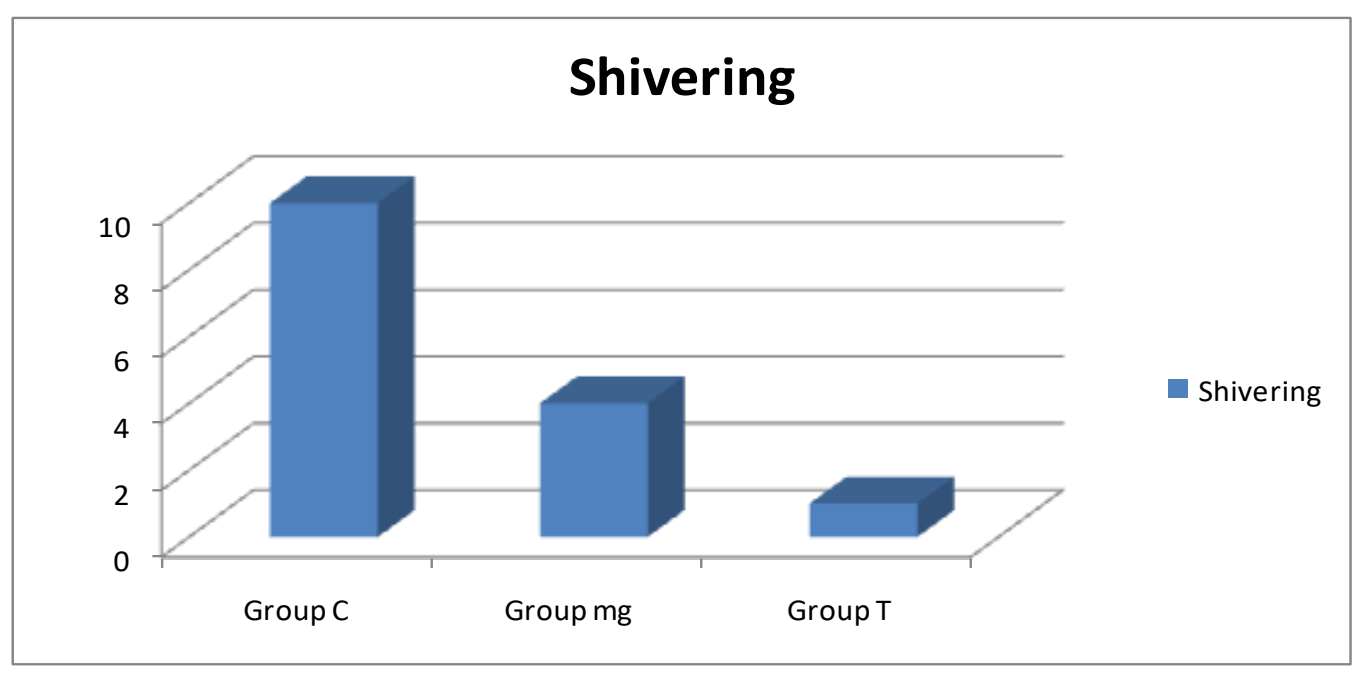

Figure (4): Shivering incidence at different times among the three groups

\section{DISCUSSION}

The present study compared the efficacy of i.v. $\mathrm{MgSO}_{4}$ and tramadol to placebo normal saline on the incidence and severity of post-spinal shivering in geriatric patients undergoing TURP surgery. We found that i.v. $\mathrm{MgSO}_{4}$ and tramadol significantly reduced the incidence and grades of shivering when used as a prophylaxis.

The present study showed no significant difference among the studied groups as regards heart rate (HR), mean arterial pressure (MAP) and $\mathrm{SPO}_{2}$. These results are in agreement with a randomized double-blind cross-sectional study of Javaherforoosh et al. ${ }^{(13)}$ who concluded that there was no significant differences between tramadol (in dose of $1 \mathrm{mg} / \mathrm{kg}$ ) and control group regarding heart rate (HR), mean arterial blood pressure (MAP) and oxygen saturation (SPO2). Additionally, hypotension was not statistically significant in the study by Ibrahim et al. ${ }^{(14)}$ who stated that the incidence was being $15 \%$. Also, Elsonbaty et al. ${ }^{(15)}$ reported that hypotension was observed in two patients who received pethidine and one patient who received magnesium. A several studies suggested that higher dose of magnesium is associated with peripheral vasodilatation with consequent hypotension, bradycardia, and hypothermia $(\mathbf{1 6}, \mathbf{1 7}$. Therefore, the dose of $\mathrm{Mg}$ used in this study was $15 \mathrm{mg} / \mathrm{kg}$. 
The present study showed that there was a change in temperature between the studied groups. Control group was significantly lowest regarding temperature followed by magnesium group then tramadol group. This result is in agreement with Tewari et al. (10) who observed a significant fall in the tympanic membrane temperature in the control group as compared to tramadol group $(\mathrm{P}<0.001)$. However, Sachidananda $\boldsymbol{e t}$ al. ${ }^{(18)}$ revealed that the mean temperature changes was comparable among tramadol, magnesium and control groups at all study points. As their study didn't find any correlations between the incidence of shivering and the changes of temperature.

In the current study, tramadol group and magnesium group reduced the incidence, severity and duration of shivering. This result is in agreement with Gozdemir et al. ${ }^{(17)}$ who stated that $\mathrm{MgSO}_{4} 80 \mathrm{mg} / \mathrm{kg}$ i.v. administered as bolus over 30 min followed by infusion of $2 \mathrm{~g} / \mathrm{h}$ significantly reduced shivering in patients receiving spinal anesthesia for transurethral resection of prostate though it increased the risk of hypothermia. Shivering occurred in $6.7 \%$ of patients who received magnesium and $66.7 \%$ of patients who received saline.

All the above studies support the use of i.v. tramadol and i.v. $\mathrm{MgSO}_{4}$ either as equally effective or superior to various drugs studied. Tramadol is safe with lesser sideeffects. Also it is easily available and so both of tramadol and $\mathrm{MgSO}_{4}$ can be used as a prophylactic in geriatric patients undergoing TURP surgery.

\section{CONCLUSIONS}

Prophylactic administration of i.v. tramadol in a dose of $0.5 \mathrm{mg} / \mathrm{kg}$ immediately after $\mathrm{SAB}$ could significantly reduce the incidence and severity of postspinal shivering more than i.v. $\mathrm{MgSO}_{4}$ in a dose of 15 $\mathrm{mg} / \mathrm{kg}$ in geriatric patients undergoing TURP surgery.

\section{REFERENCES}

1. Collins S, Budds M, Raines C et al. (2019): Risk Factors for Perioperative Hypothermia: A Literature Review. Journal of PeriAnesthesia Nursing, 34 (2): 338-346.

2. Lenhardt $\mathbf{R}$ (2018): Body temperature regulation and anesthesia. In Handbook of Clinical Neurology, 157: 635644.

3. Ghasemi M, Behnaz F, Hajian H (2018): The effect of dexmedetomidine prescription on shivering during operation in the spinal anesthesia procedures of selective orthopedic surgery of the lower limb in addicted patients. Anesthesiology and Pain Medicine, 8 (2): 63230-36.

4. Lopez M (2018): Postanaesthetic shivering-from pathophysiology to prevention. Romanian Journal of Anaesthesia and Intensive Care, 25 (1): 73-81.

5. Tekgül Z, Horsanali B, Horsanali M (2017): Anesthesia for Urological Surgery. Current Topics in Anesthesiology, 17: 53-97.
6. Ebied R, Ali M, Khafagy H et al. (2016): Comparative study between continuous epidural anaesthesia and continuous Wiley Spinal ${ }^{\circledR}$ anaesthesia in elderly patients undergoing TURP. Egyptian Journal of Anaesthesia, 32 (4): 527-533.

7. Binette A, Blouin S, Ardilouze A et al. (2017): Neuroprotective effects of antenatal magnesium sulfate under inflammatory conditions in a Sprague-Dawley pregnant rat model. The Journal of Maternal-Fetal \& Neonatal Medicine, 30 (14): 1715-1720.

8. Mostafa M, Hassan Z, Hassan S (2019): Corrected and republished: shivering prevention during cesarean section by intrathecal injection of magnesium sulfate: randomized double-blind controlled study. Res Opin Anesth Intensive Care, 6: 252-8.

9. Bravo L, Mico J, Berrocoso E (2017): Discovery and development of tramadol for the treatment of pain, Expert Opin. Drug Discov., 12: 1281-1291.

10. Tewari A, Dhawan I, Mahendru V et al. (2014): Use of oral tramadol to prevent perianesthetic shivering in patients undergoing transurethral resection of prostate under subarachnoid blockade. Saudi Journal of Anaesthesia, 8 (1): 11-16.

11. Subedi M, Bajaj S, Kumar M et al. (2019): An overview of tramadol and its usage in pain management and future perspective. Biomedicine \& Pharmacotherapy, 111: 443451.

12. Crossley A, Mahajan R (1994): The intensity of postoperative shivering is unrelated to axillary temperature. Anaesthesia, 49 (3): 205-207.

13. Javaherforoosh $\mathrm{F}$, Akhondzadeh $\mathrm{R}$, Aein $\mathrm{K}$ et al. (2009): Effects of tramadol on post spinal anesthesia shivering in electivecesarean section. Pak J Med Sci., 25: $12-7$.

14. Ibrahim I, Megalla S, Khalifa O et al. (2014): Prophylactic vs. Therapeutic magnesium sulfate for shivering during spinal anesthesia. Egypt J Anesth., 30: 31-7.

15. Elsonbaty M, Elsonbaty A, Saad D (2013): Is this time for magnesium sulfate to replace meperidine as an antishivering agent in spinal anesthesia? Egypt J Anesth., 29: 213-7.

16. Jee $\mathrm{D}$, Lee $\mathrm{D}$, Yun $\mathrm{S}$ et al. (2009): Magnesium sulfate attenuates arterial pressure increase during laparoscopic cholecystectomy underpneumoperitoneum. Br J Anaesth., 103: 484-9.

17. Gozdemir M, Usta B, Demircioglu $R$ et al. (2010): Magnesium sulfate infusion prevents shivering during transurethral prostatectomy with spinal anesthesia: a randomized, double-blinded, controlled study. Journal of Clinical Anesthesia, 22 (3): 184-189.

18. Sachidananda R, Basavaraj K, Shaikh $S$ et al. (2018): Comparison of prophylactic intravenous magnesium sulfate with tramadol for postspinal shivering in elective cesarean section: a placebo controlled randomized double-blind pilot study. Anesthesia, Essays and Researches, 12 (1): 130-136. 